\title{
Ultra-High-Speed Optical Serial-to-Parallel Data Conversion in a Silicon Nanowire
}

Mulvad, Hans Christian Hansen; Palushani, Evarist; Hu, Hao; Ji, Hua; Galili, Michael; Clausen, Anders; Pu, Minhao; Yvind, Kresten; Hvam, Jørn Märcher; Jeppesen, Palle

Total number of authors:

11

Published in:

Proceedings of the European Conference on Optical Communication (ECOC) 2011

Publication date:

2011

Document Version

Publisher's PDF, also known as Version of record

Link back to DTU Orbit

Citation $(A P A)$ :

Mulvad, H. C. H., Palushani, E., Hu, H., Ji, H., Galili, M., Clausen, A., Pu, M., Yvind, K., Hvam, J. M., Jeppesen, P., \& Oxenløwe, L. K. (2011). Ultra-High-Speed Optical Serial-to-Parallel Data Conversion in a Silicon Nanowire. In Proceedings of the European Conference on Optical Communication (ECOC) 2011 (pp. Th.13.A.2). Optical Society of America. http://www.ecoc2011.org/

\section{General rights}

Copyright and moral rights for the publications made accessible in the public portal are retained by the authors and/or other copyright owners and it is a condition of accessing publications that users recognise and abide by the legal requirements associated with these rights.

- Users may download and print one copy of any publication from the public portal for the purpose of private study or research.

- You may not further distribute the material or use it for any profit-making activity or commercial gain

- You may freely distribute the URL identifying the publication in the public portal 


\title{
Ultra-High-Speed Optical Serial-to-Parallel Data Conversion in a Silicon Nanowire
}

\author{
H.C. Hansen Mulvad, E. Palushani, H. Hu, H. Ji, M. Galili, A.T. Clausen, M. Pu, K. Yvind, J.M. Hvam, \\ P. Jeppesen and L.K. Oxenløwe \\ DTU Fotonik, Department of Photonics Engineering, Technical University of Denmark, Building 343, DK-2800 Kgs. Lyngby, Denmark \\ hchm@fotonik.dtu.dk
}

\begin{abstract}
We demonstrate conversion from $64 \times 10 \mathrm{Gbit} / \mathrm{s}$ OTDM to $25 \mathrm{GHz}$ DWDM by timedomain optical Fourier transformation. Using a single silicon nanowire, 40 of 64 OTDM tributaries are simultaneously converted to DWDM channels within FEC limits. OCIS codes: (060.4510) Optical communications; (190.4380) Nonlinear optics, four-wave mixing.
\end{abstract}

\section{Introduction}

Optical signal processing (OSP) relies on optical effects with intrinsic response times down to a few femtoseconds, which allows for operation speeds of several Tbit/s without an associated increase in energy consumption as seen in electronics. OSP appears best suited for relatively simple functionalities such as wavelength conversion where large amounts of data are processed simultaneously in a single device, in order to achieve low switching energy per bit [1,2]. Serial-to-parallel conversion is another attractive functionality, and if performed in a single device, this has many similarities to wavelength conversion, including potential for low switching energy. Furthermore, siliconbased OSP is attracting considerable interest due to its CMOS compatibility, integration potential with electronics, low cost and broad operation bandwidth [2-4].

In this paper, we demonstrate the first optical serial-to-parallel conversion in a silicon device using four-wave mixing (FWM) based time-domain optical Fourier transformation (OFT) [5]. The principle allows a bit-rate scalable and spectrally efficient conversion of serial optical time-division multiplexed (OTDM) data to the dense wavelength division multiplexed (DWDM) format [6,7]. More than half of all OTDM tributaries can be converted in a single device [7], meaning that with only two devices, all tributaries may be simultaneously demultiplexed/converted to DWDM. Here, we experimentally demonstrate simultaneous conversion of 40 out of 64 consecutive $10 \mathrm{Gbit} / \mathrm{s}$ tributaries in a $640 \mathrm{Gbit} / \mathrm{s}$ OTDM-DPSK data signal onto a $25 \mathrm{GHz}$ ITU DWDM grid, with a BER performance within the standard FEC limit of $2 \times 10^{-3}$. We also perform a demonstration on $640 \mathrm{Gbit} / \mathrm{s}$ OTDM-OOK data in a $50 \mathrm{~m}$ highly non-linear fibre (HNLF), where the higher FWM conversion efficiency enables error-free performance $\left(\mathrm{BER}<10^{-9}\right)$ for 43 out of 64 converted tributaries.

\section{Principle and experimental set-up}

OFT is achieved by propagation of the OTDM data through a medium with second order chromatic dispersion $D$, followed by parabolic phase-modulation with a chirp rate $K[4,7]$. The OFT transfers the OTDM time-intensity profile into the spectral domain, provided the condition $D=1 / K$ is fulfilled. The scaling of the time-to-frequency mapping is determined by $\Delta v=K \times \Delta \tau$. Here, the parameters are chosen such that a $640 \mathrm{Gbit} / \mathrm{s}$ tributary spacing $\Delta \tau=1.56 \mathrm{ps}$ is mapped to a DWDM spacing $\Delta v=25 \mathrm{GHz}$. The phase-modulation is achieved in a FWM process using linearly chirped flat-top pump pulses. The pump chirp and data chirp are combined in the idler signal where they cancel each other, thus converting the OTDM tributaries to spectrally compressed DWDM channels.

The experimental set-up is shown in Fig. 1. The OTDM data signal and the pump pulses for the FWM process are obtained from two $10 \mathrm{GHz}$ erbium glass oscillating pulse-generating lasers at $1542 \mathrm{~nm}$ (ERGO-PGL1) and $1557 \mathrm{~nm}$ (ERGO-PGL2), respectively, both emitting $\sim 1.5$ ps full-width at half-maximum (FWHM) pulses, cf. Fig. 1 (a). In both cases, the ERGO-PGL output pulses undergo self-phase modulation (SPM) in dispersion-flattened highly non-linear fibres (DF-HNLF) with normal dispersion, in order to generate a broadened flat-top spectrum. In the case of the data signal, the output spectrum of DF-HNLF1 is filtered at 1547 nm with a $13 \mathrm{~nm}$ optical bandpass filter (BPF). The resulting pulses are data-modulated with a $10 \mathrm{Gbit} / \mathrm{s} 2^{31}-1$ PRBS pattern in a push-pull MachZehnder modulator (MZM) to obtain either differential phase-shift keying (DPSK) format (in the case of silicon), or on-off keying (OOK) (in the case of HNLF). The $10 \mathrm{Gbit} / \mathrm{s}$ pulses are subsequently multiplexed to $640 \mathrm{Gbit} / \mathrm{s}$ single polarisation OTDM using passive fibre-based delay-line multiplexer stages (MUX). Finally, the data spectrum is shaped into a Gaussian-like spectrum of 3-dB bandwidth $\sim 6.1 \mathrm{~nm}$ at $1547 \mathrm{~nm}$ using a wavelength selective switch WSS 1 (Finisar Waveshaper 4000S), resulting in near transform-limited Gaussian pulses of FWHM 615 fs. To obtain the pump pulses, the output spectrum of DF-HNLF2 is filtered using another WSS (WSS2), programmed 


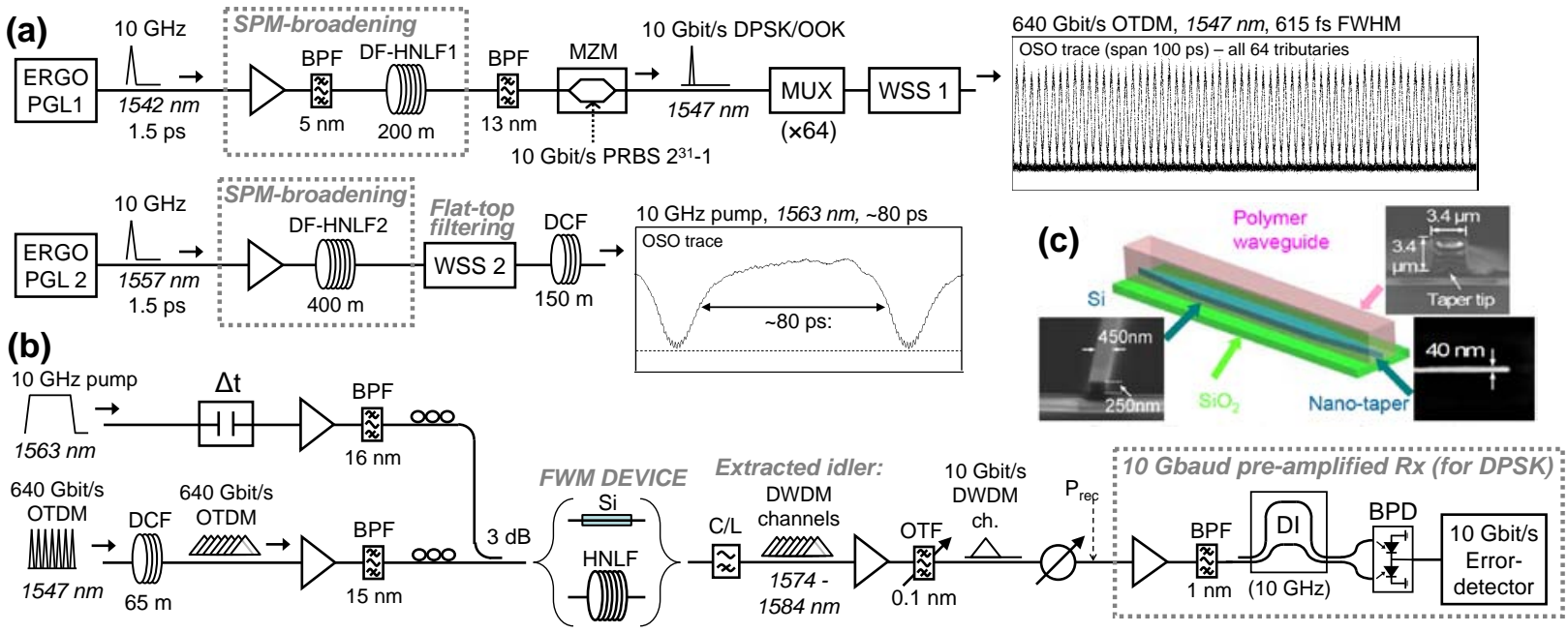

Fig. 1. (a), (b) Experimental set-up, (c) Schematic drawing of the nano-engineered silicon waveguide and scanning electron micrograph pictures of the sample. Insets: OSO traces of the $640 \mathrm{Gbit} / \mathrm{s}$ OTDM data (upper right) and the $10 \mathrm{GHz}$ pump pulse (middle).

with a $5^{\text {th }}$ order super-Gaussian of 3-dB bandwidth $5.4 \mathrm{~nm}$ centered at $1563 \mathrm{~nm}$. The WSS2 output pulses are propagated through a $150 \mathrm{~m}$ dispersion-compensating fibre (DCF), resulting in a linearly chirped waveform with a $\sim 80$ ps wide flat-top shape. Optical sampling oscilloscope (OSO) traces of the $640 \mathrm{Gbit} / \mathrm{s}$ OTDM pulses and the pump pulses are shown as insets in Fig. 1. Next, the $640 \mathrm{Gbit} / \mathrm{s}$ OTDM data and pump signals enter the OFT-based OTDM-DWDM converter, c.f. Fig. 1 (b). As the first step in the OFT, the OTDM pulses are dispersed in a $65 \mathrm{~m}$ DCF $(D)$. The OTDM and pump signals are then amplified, filtered, and combined using a $3 \mathrm{~dB}$ coupler before undergoing FWM in either a silicon waveguide or a HNLF. The HNLF has a length of $50 \mathrm{~m}$, non-linear coefficient $\gamma \sim 10 \mathrm{~W}^{-1} \mathrm{~km}^{-1}$, zero-dispersion wavelength $\sim 1565 \mathrm{~nm}$ and dispersion slope $0.02 \mathrm{ps} /\left(\mathrm{nm}^{2} \cdot \mathrm{km}\right)$. The silicon nanowire is a dispersion engineered straight $3.6 \mathrm{~mm}$ long silicon waveguide which includes tapering sections for low loss interfacing with optical fiber, as shown in Fig. 1 (c). The main waveguide section is $\sim 3 \mathrm{~mm}$ long and has a crosssectional dimension of $250 \mathrm{~nm} \times 450 \mathrm{~nm}$. The measured propagation loss is $4.3 \mathrm{~dB} / \mathrm{cm}$ and the fiber-to-fiber loss of the device is $4.5 \mathrm{~dB}$ [2]. The input power to the tapered fibre before the silicon waveguide is $22.0 \mathrm{dBm}$ for the pump and $12.6 \mathrm{dBm}$ for the OTDM signal. The same power levels are used as input to the HNLF.

After FWM, the DWDM signal (idler) in the L-band is isolated using a C/L-band splitter and then amplified using an L-band EDFA. The individual DWDM channels are extracted using an optical tunable filter (OTF) of bandwidth $\sim 0.1 \mathrm{~nm}$ (Santec OTF-350), c.f. filter profile in Fig. 2 (a), inset. The BER performance of each DWDM channel is measured in a $10 \mathrm{Gbit} / \mathrm{s}$ pre-amplified receiver (Rx). In the case of DPSK, a delay-interferometer (DLI) and balanced photo-detection (BPD) replace the single-ended photo-detection used for OOK. Note that a $10 \mathrm{GHz}$ synthesizer is used to synchronise the ERGO-PGLs, the PRBS pattern generator, and the receiver.

\section{Results}

The successful OTDM-to-DWDM conversion in the silicon nanowire is shown in Fig. 2. The output spectrum of the silicon waveguide is shown in Fig. 2 (a). The inset shows a close-up of the centre of the DWDM spectrum, both for a $640 \mathrm{Gbit} / \mathrm{s}$ and $160 \mathrm{Gbit} / \mathrm{s}$ OTDM rate (same average power). A successful OFT mapping of the Gaussian OTDM pulses into individual $25 \mathrm{GHz}$ spaced spectral channels can be observed. For BER evaluation, all converted
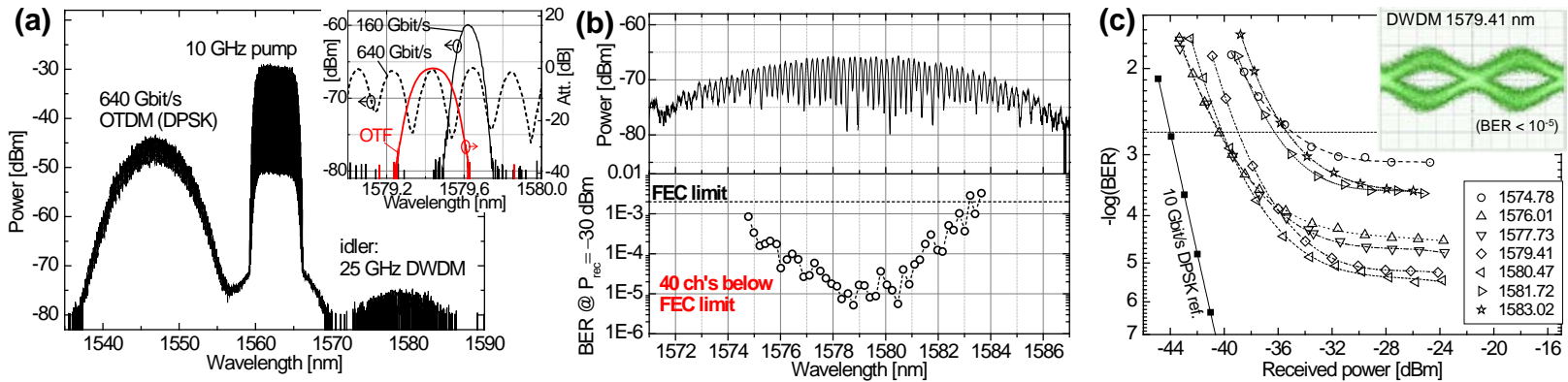

Fig. 2. Results for silicon nanowire. (a) Output spectrum of silicon (Inset: zoom-in on idler DWDM spectrum in the cases of $160 \mathrm{Gbit} / \mathrm{s}$ and $640 \mathrm{Gbit} / \mathrm{s}$ OTDM and OTF transfer function, res. $0.01 \mathrm{~nm}$ ). (b) DWDM spectrum (above) and BER performance of each DWDM channel at $\mathrm{P}_{\mathrm{rec}}=-30 \mathrm{dBm}$ (below). (c) $10 \mathrm{Gbit} / \mathrm{s}$ DPSK BER curves for selected DWDM channels (Inset: $10 \mathrm{Gbit} / \mathrm{s}$ demodulated DPSK eye diagram). 
DWDM channels are individually extracted by the tunable filter (while keeping the relative timing of pump and OTDM signal fixed by precise control of the time-delay $\Delta$ t, c.f. Fig. 1 (b)). A total of 40 consecutive tributaries are converted with a BER performance below the FEC limit of $2 \times 10^{-3}$, as shown in Fig. 2 (b). Fig. 2 (c) shows BER curves for selected DWDM channels. It can be observed in Fig. 2 (a) and (c) that the BER deteriorates for DWDM channels towards the sides of the DWDM spectrum. These channels originate from dispersed OTDM tributaries that are only partly overlapped by the $\sim 80$ ps pump pulse in the FWM process. Therefore, these channels suffer from lower conversion efficiency as well as spectral broadening leading to inter-channel cross-talk. The observed errorfloor for all channels is attributed to a low OSNR due to the limited conversion efficiency (-32 dB) of our silicon sample. Assuming FEC can be applied, the demonstrated BER performance allows for a net error-free OTDM data rate of $595 \mathrm{Gbit} / \mathrm{s}$. A significantly better BER performance is expected for silicon waveguides with lower propagation loss and therefore higher conversion efficiency [3]. Indeed, the strong potential of the technique is confirmed by the good performance achieved for the $640 \mathrm{Gbit} / \mathrm{s}$ OOK OTDM-DWDM conversion in the HNLF. The HNLF output spectrum is shown in Fig. 3 (a). In this case, the FWM conversion efficiency is significantly better $(-24 \mathrm{~dB})$ and the DWDM channels do not suffer excessively from OSNR limitations. The sensitivities of all channels with BER $<10^{-9}$ are shown in Fig. 3 (b) and selected BER curves in Fig. 3 (c). A total of 43 channels have error-free performance, and 32 channels (half of all tributaries) display a power penalty of only 3-5 $\mathrm{dB}$ compared to the $10 \mathrm{Gbit} / \mathrm{s}$ L-band reference curve (50\% RZ-OOK, measured after the MZM).
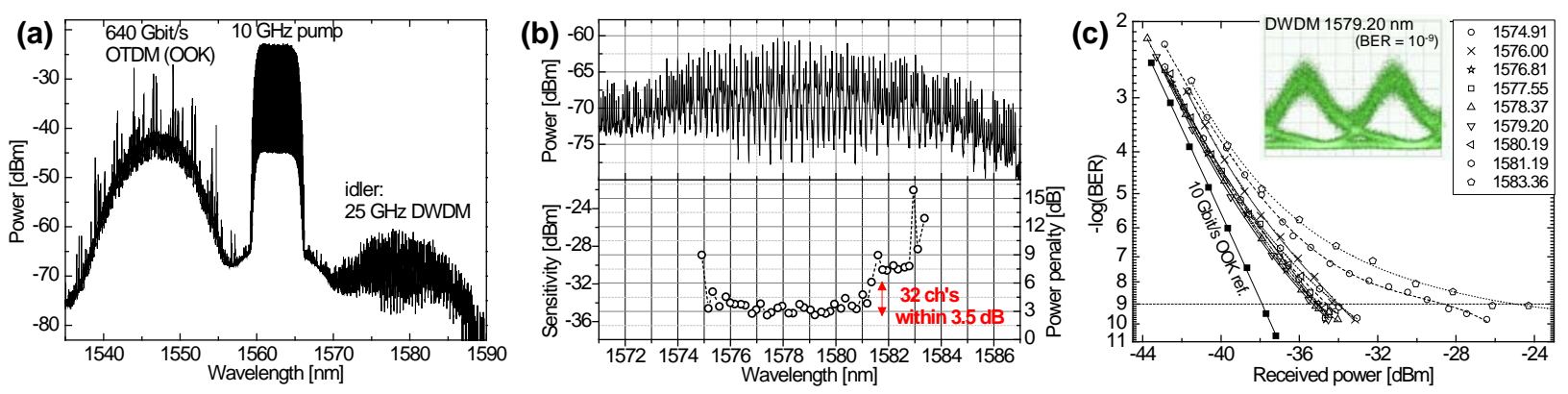

Fig. 3. Results for HNLF. (a) Output spectrum of HNLF. (b) DWDM spectrum (above) and sensitivity of each DWDM channel (required $P_{\text {rec }}$ for $\mathrm{BER}=10^{-9}$ ) (below). (c) $10 \mathrm{Gbit} / \mathrm{s}$ OOK BER curves for selected DWDM channels (Inset: $10 \mathrm{Gbit} / \mathrm{s}$ OOK eye diagram at $\mathrm{BER}=10^{-9}$ ).

\section{Conclusion}

For the first time, we have experimentally demonstrated optical serial-to-parallel conversion from $640 \mathrm{Gbit} / \mathrm{s}$ OTDM to $25 \mathrm{GHz}$ DWDM in both a $3.6 \mathrm{~mm}$ silicon waveguide and a $50 \mathrm{~m}$ HNLF, based on time-domain OFT. In silicon, more than half of all OTDM tributaries (40/64) were converted with a BER performance within FEC limits. In HNLF, more than half of the tributaries (43/64) were converted with error-free performance. These successful demonstrations underline the high potential of optical signal processing for ultra-high bit rates. In particular, the demonstrated technique could result in a simplified OTDM receiver with demultiplexing of all tributaries using only two OFT devices.

\section{References}

[1] K. Hinton, G. Raskutti, P. M. Farrell, and R. S. Tucker, "Switching Energy and Device Size Limits on Digital Photonic Signal Processing Technologies,” IEEE Journal of Selected Topics in Quantum Electronics 14, 938-945 (2008).

[2] H. Hu, H. Ji, M. Galili, M. Pu, H.C.H. Mulvad, K. Yvind, J.M. Hvam, P. Jeppesen, and L.K. Oxenløwe, "Silicon Chip based Wavelength Conversion of Ultra-High Repetition Rate Data Signals,” Conference on Optical Fiber Communication, OFC 2011, paper PDPA8 (2011).

[3] M. A. Foster, A. C. Turner, R. Salem, M. Lipson, and A. L. Gaeta, "Broad-band continuous-wave parametric wavelength conversion in silicon nanowaveguides”, Opt. Express 15, 12949 (2007).

[4] H. Ji, H. Hu, M. Galili, L.K. Oxenløwe, M. Pu, K. Yvind, J.M. Hvam, and P. Jeppesen, “Optical waveform sampling and error-free demultiplexing of 1.28 Tbit/s serial data in a silicon nanowire," Conference on Optical Fiber Communication, OFC 2010, paper PDPC7 (2010).

[5] M. Nakazawa, T. Hirooka, F. Futami, and S. Watanabe,"Ideal distortion-free transmission using optical Fourier transformation and Fourier transform-limited optical pulses”, IEEE Photon. Technol. Lett., 16, 1059-1061 (2004)

[6] H. C. H. Mulvad, E. Palushani, M. Galili, J. Xu, H. Hu, A. Clausen, L. Oxenløwe, and P. Jeppesen, "OTDM-WDM conversion based on timedomain optical Fourier transformation with spectral compression”, Optical Fiber Communication Conference, OFC 2011, paper OThN2 (2011).

[7] E. Palushani, H.C.H. Mulvad, M. Galili, H. Hu, L.K. Oxenløwe, A. Clausen, and P. Jeppesen, “OTDM-to-WDM Conversion Based on Timeto-Frequency Mapping by Time-Domain Optical Fourier Transformation”, IEEE JSTQE, DOI: 10.1109/JSTQE.2011.2131121, in press (2011). 